\title{
Perturbations in Effort-Related Decision-Making Driven by Acute Stress and Corticotropin-Releasing Factor
}

\author{
Courtney A Bryce' and Stan B Floresco*,I \\ 'Department of Psychology and Brain Research Centre, University of British Columbia, Vancouver, BC, Canada
}

\begin{abstract}
Acute stress activates numerous systems in a coordinated effort to promote homeostasis, and can exert differential effects on mnemonic and cognitive functions depending on a myriad of factors. Stress can alter different forms of cost/benefit decision-making, yet the mechanisms that drive these effects remain unclear. In the present study, we probed how corticotropin-releasing factor (CRF) may contribute to stress-induced alterations in cost/benefit decision-making, using an task where well-trained rats chose between a low effort/ low reward lever (LR; two pellets) and a high effort/high reward lever (HR; four pellets), with the effort requirement increasing over a session (2, 5, 10, and 20 presses). One-hour restraint stress markedly reduced preference for the HR option, but this effect was attenuated by infusions of the CRF antagonist, alpha-helical CRF. Conversely, central CRF infusion mimicked the effect of stress on decision-making, as well as increased decision latencies and reduced response vigor. CRF infusions did not alter preference for larger vs smaller rewards, but did reduce responding for food delivered on a progressive ratio, suggesting that these treatments may amplify perceived effort costs that may be required to obtain rewards. CRF infusions into the ventral tegmental area recapitulated the effect of central CRF treatment and restraint on choice behavior, suggesting that these effects may be mediated by perturbations in dopamine transmission. These findings highlight the involvement of CRF in regulating effort-related decisions and suggest that increased CRF activity may contribute to motivational impairments and abnormal decision-making associated with stress-related psychiatric disorders such as depression. Neuropsychopharmacology (2016) 4I, 2147-2159; do:10.1038/npp.2016.15; published online 24 February 2016
\end{abstract}

\section{INTRODUCTION}

Acute stress activates numerous systems in a coordinated response to promote energy availability, adaptive behaviors, and return the organism to homeostasis. At the same time, stress has also been implicated as a key contributing factor for a variety of psychiatric disorders, most notably depression. Among the numerous behaviors altered by acute stress, its effects on learning, memory, and cognition has been the subject of considerable research. Learning and memory can be differentially affected by acute stress, dependent on a myriad of factors including the context, duration, and timing of the stressor (Shors et al, 1992; Cordero et al, 2003; Kim et al, 2007; de Quervain et al, 1998; Diamond and Rose, 1994). Similarly, stress can also exert sometimes-opposing effects on certain executive functions mediated by the frontal lobes. Working memory and different forms of cognitive flexibility have been shown to be either impaired (Arnsten and Goldman-Rakic, 1998; Shansky et al, 2006; Arnsten, 2009; Butts et al, 2011, 2013) or augmented (Yuen et al, 2009; Bryce and Howland, 2015) by acute stress. As it is now recognized that stress-related psychiatric disorders are

\footnotetext{
*Correspondence: Dr SB Floresco, Department of Psychology and Brain Research Center, University of British Columbia, 2136 West Mall, Vancouver, BC V6T IZ4, Canada, Tel: +604 827 53।3, Fax: +604 822 6923, E-mail: floresco@psych.ubc.ca

Received 15 December 2015; revised 26 January 2016; accepted 27 January 2016; accepted article preview online 2 February 2016
}

associated with impairments in cognition, understanding the mechanisms through which stress affects these functions may help clarify the relationship between psychopathology and cognitive dysfunction.

Decision-making processes entailing evaluations of relative costs and benefits associated with different actions are also susceptible to disruption by acute stress. Studies in humans have shown that different forms of acute stress can lead to disadvantageous or more automatized patterns of decisionmaking when choosing between options associated with different magnitudes and probabilities of obtaining rewards (Starcke et al, 2008; Porcelli and Delgado 2009; Pabst et al, 2013). Similarly, studies by our group have shown that acute restraint stress in rats induces a reliable and pronounced reduction in preference for larger rewards associated with greater effort costs, as well as an increase in decision latencies (Shafiei et al, 2012). The observation is particularly interesting in light of the fact that patients diagnosed with depression also show reduced preference to work harder for larger rewards in a back-translated effort-based decisionmaking task (Treadway et al, 2012). It is therefore plausible that elucidation of the mechanisms through which acute stress can reduce preference for more preferred yet higher cost rewards may provide an insight into the pathophysiology underlying motivational deficits and anergia associated with depression.

It is well established that acute stress promotes corticosterone release, and also enhances dopamine transmission in 
the prefrontal cortex (Jedema and Moghaddam, 1994; Jackson and Moghaddam, 2004; Butts et al, 2011). However, the effects of stress on effort-related decision-making did not appear to be driven by these factors. Pharmacological antagonism of dopamine receptors did not alter the effects of restraint stress on effort-related choice, and treatment with physiologically relevant doses of corticosterone did not recapitulate the effects of stress on this form of decisionmaking (Shafiei et al, 2012). This indicates that other neurochemical mechanisms activated by stress may mediate its effects on cost/benefit decision-making. In this regard, corticotropin-releasing factor (CRF) is one neurochemical signal that acts centrally to mediate many of the behavioral effects of acute stress, including stress-induced anxiety, aversion, and drug-seeking behavior (Müller et al, 2003; Cador et al, 1992; Koob, 2010). CRF receptors are widely expressed in cortical and subcortical regions, including in the prefrontal cortex, nucleus accumbens, and amygdala and in particular, mesencephalic regions including dopamine neurons in the ventral tegmental area (VTA; Van Pett et al, 2000; Bittencourt and Sawchenko, 2000). Acute stress can stimulate the release of CRF into the VTA (Wang et al, 2005) and infusion of CRF into the VTA can attenuate both rewardassociated mesoaccumbens dopamine release and motivation to work for food rewards (Wanat et al, 2013).

The observation that CRF can attenuate mesoaccumbens dopamine release is interesting in light of the overwhelming evidence that intact dopamine functioning has a key role in enabling animals to overcome effort-related costs. Reducing dopamine transmission, either systemically or within the nucleus accumbens, decreased preference of the more effortful option (Salamone et al, 1991, 1994; Floresco, et al, 2008), in a manner similar to the effects of acute stress. In light of these considerations, the present study was conducted to clarify a potential contribution of CRF transmission to the effects of acute stress on cost/benefit decision-making. Specifically, we investigated whether (i) blockade of CRF receptors could attenuate the effects of acute stress on decision-making and (ii) intra-cerebral administration of CRF mimics the behavioral effects of stress.

\section{MATERIALS AND METHODS}

\section{Animals}

Separate cohorts of male Long Evans rats weighing 250$275 \mathrm{~g}$ at the beginning of training were utilized for all experiments. Following 1 week of colony acclimatization, rats were individually housed and food-restricted to $85 \%$ of their free-feeding weight prior to the commencement of operant chamber training. Water was provided ad libitum for the duration of the experiment. Body weight was monitored daily and rat chow was provided immediately following operant chamber training each day. All testing was carried out in accordance with the Canadian Council of Animal Care and the Animal Care Committee of the University of British Columbia.

\section{Apparatus}

Behavioral testing was conducted in operant chambers $(30.5 \times 24 \times 21 \mathrm{~cm}$; Med-Associates, St Alban, VT, USA $)$ enclosed in a sound-attenuating box. Each box was equipped with a fan with the purpose of providing ventilation and limiting extraneous sounds. The chamber was fitted with a central food receptacle where sugar pellets $(45 \mathrm{mg}$; Bioserv, Frenchtown, NJ) were dispensed. Two retractable levers were located on either side of the food receptacle. The operant chamber was illuminated by a $100-\mathrm{mA}$ house light located on the top center of the box opposite the food receptacle. Experimental data were recorded by a personal computer connected to the operant chambers via an interface.

\section{Behavioral Tasks}

Effort discounting. After initial lever training (see Supplementary Methods) separate cohorts of rats were trained 5-7 days a week on the effort-based decision-making task as described previously (Floresco et al, 2008; GhodsSharifi and Floresco, 2010). Each 32-min daily training session consisted of 48 trials separated into four blocks. Trials were initiated on $40 \mathrm{~s}$ intervals by the illumination of the house light and $2 \mathrm{~s}$ later, extension of one or both levers. Each of the four blocks began with two forced choice trials in which only one of the two levers was randomly extended. The remainder of the trials were free-choice trials, where both levers were presented and the rats choose between the two options. For all sessions and blocks, one lever was designated as the low reward lever (LR) and the other lever was designated as the high reward lever (HR) (counterbalanced). Following presentation of the levers, rats were required to make a response by pressing one of the levers within $25 \mathrm{~s}$ of insertion. The failure to respond to either lever was scored as an omission with the operant chamber returned to an inter-trial state. Selection of the LR lever caused both levers to retract and the rat would receive two pellets. Conversely, if the rat chose the HR lever, only the LR lever retracted and the HR lever remained extended until the rat made the requisite number of presses to obtain four pellets, or $25 \mathrm{~s}$ elapsed from time of insertion. The number of presses required increased over subsequent blocks, with the requirement initially set at 2 presses, and increasing to 5,10 , and 20 presses for subsequent blocks. The house light remained illuminated for an additional $4 \mathrm{~s}$ after the delivery of the final pellet, after which the chamber was set to the inter-trial state. On the rare occasion that a rat failed to complete the required number of presses within $25 \mathrm{~s}$, the lever retracted, no food was delivered, and the chamber returned to the inter-trial state. However, the rat's choice was still incorporated into the analysis. Other measures incorporated into the analysis included choice latency (the time between lever extension and choice) and rates of pressing on the HR lever.

Rats were trained on the task until as a group, they (i) chose the HR lever during the first trial block on at least 75\% of the free-choice trials and (ii) demonstrated stable baseline levels of discounting for three consecutive days. Stability was analyzed using a $3 \times 4$ repeated measures analysis of variance (ANOVA) with training day (3) and trial block (4) as withinsubjects factors. The animals were judged to have achieved stability of choice behavior when there was no main effect of day or day $\times$ trial block interaction $(p>0.10)$.

Reward magnitude discrimination. A separate cohort of rats received initial lever press training, after which, they 
were trained on a simpler, reward magnitude discrimination. This task equated the costs of the two levers so that a single press on the LR lever delivered two pellets, and one press on the HR lever delivered four pellets. Each session consisted of 48 trials ( $40 \mathrm{~s}$ inter-trial interval), with 12 trials per block (2 forced-choice trials followed by 10 free-choice trials). Rats were trained for 9 days and displayed a strong preference for the HR lever ( $90 \%)$ at the end of this period prior to drug testing.

Progressive ratio tests. A separate cohort of animals was trained to press a single lever for food delivered on a progressive ratio schedule. Over daily training sessions, the left lever remained extended in the operant chamber. During the initial training, responses were reinforced on an FR1 schedule for 2 days followed by 1 day on an FR2 schedule and 2 days on an FR5 schedule. Completing a ratio delivered one pellet. Next, rats were trained on the progressive ratio schedule, in which the number of presses required to obtain a pellet increased exponentially. The ratio was adapted from the one used by Brown et al (1998) and increased in the following manner: $1,2,4,6,9,12,15,20,25,32,40,50,62$, $77,95,118,145,178,219,268,328,402,492,693,737$, and 901 presses. Rats had a maximum of $20 \mathrm{~min}$ to complete each ratio and obtain reward. Failure to complete a ratio in the allotted time ended the session. The primary variables of interest were: (i) the total number of lever presses over the course of a session and (ii) the last ratio obtained before a session terminated (breakpoint). The program also recorded the time intervals between the delivery of each pellet, and these values were divided by the number of responses required to obtain that pellet to generate an average response rate for each ratio. Training continued for 10 days on this task, until rats displayed stable levels of lever pressing and breakpoints for three consecutive days as a group (ie, less than $15 \%$ variation within the group).

\section{Surgery}

Rats were anaesthetized using ketamine $(100 \mathrm{mg} / \mathrm{kg}$, IP)/ xylazine $(10 \mathrm{mg} / \mathrm{kg}, \mathrm{IP}$ ) and given analgesic (Anafen, $10 \mathrm{mg} / \mathrm{kg}$, SC) prior to surgery. The majority of animals in this study were implanted with unilateral cannula targeted $1 \mathrm{~mm}$ dorsal to the right lateral ventricle (coordinates, flat skull:AP: $-1.0 \mathrm{~mm}$ from bregma; ML, $-1.8 \mathrm{~mm}$; DV, $-2.5 \mathrm{~mm}$ from dura). Another group of rats were implanted with bilateral cannulae $1 \mathrm{~mm}$ dorsal to the VTA (coordinates: AP: $-5.5 \mathrm{~mm}$; ML, $0.7 \mathrm{~mm}$; DV, $-7.0 \mathrm{~mm}$ ). Dental acrylic adhered to four stainless-steel skull screws held cannula in place. Stainless steel obdurators flush with the end of the guide cannula were inserted after surgery. Postoperative procedures included daily weighing and subcutaneous analgesic administration for at least 2 days following surgery. Rats were given approximately 1 week to recover from surgery before behavioral training (re)commenced. Rats trained on the effort-discounting task were implanted after initial training, whereas those trained on tasks requiring fewer session to achieve stable performance (ie, reward magnitude discrimination and progressive ratio test) were implanted prior to training.

\section{Drugs and Microinfusion Procedure}

An initial experiment tested whether the effects of acute stress on decision-making could be attenuated by intracerebroventricular (ICV) administration of the non-specific CRF antagonist alpha-helical CRF (9-41; Tocris Bioscience). Previous studies have shown that ICV infusions of this compound blocked the effect of acute stress on various behavioral measures at doses ranging from 5 to $50 \mu \mathrm{g}$ (Krahn et al, 1986; Kalin et al, 1988; Berridge and Dunn, 1989; Cole et al, 1990; Nawata et al, 2012). In the present study, we infused $30 \mu \mathrm{g} / 4 \mu \mathrm{l}$, dissolved in distilled water.

Other experiments assessed whether central infusions of CRF could mimic the effect of acute restraint stress. An initial study investigated the effects of ICV infusions of three different doses of CRF (rat/human; Tocris Bioscience; 0.25, 1 , and $3 \mu \mathrm{g}$ ) on effort discounting. Previous experiments have seen alterations in behavior following ICV infusions ranging from doses as low as 0.1 to $10 \mu \mathrm{g}$ infused into the ventricular system (Dunn and Berridge, 1990; Cador et al, 1992; Adamec and McKay, 1993; Campbell et al, 2004; Van't Veer et al, 2012). As the maximum solubility of CRF in artificial cerebrospinal fluid is $1 \mu \mathrm{g} / 1 \mu \mathrm{l}$, the infusion volume for the $3 \mu \mathrm{g}$ dose was set to $3 \mu \mathrm{l}$, whereas for the other two doses, the volume was $1 \mu \mathrm{l}$. There were no significant differences on performance following $1 \mu \mathrm{l} v s \quad 3 \mu \mathrm{l}$ vehicle infusions $(p>0.05)$, therefore data obtained after treatments with each of the three vehicle doses were averaged for the analyses. Subsequent studies using ICV infusions of CRF only used the $3 \mu \mathrm{g}$ dose. In another experiment, CRF was infused directly into the VTA $(0.5 \mu \mathrm{g} / 0.5 \mu \mathrm{l})$. This dose was selected with reference to the study by Wanat et al (2013) showing that it was effective in altering responding for sucrose on a progressive ratio schedule.

\section{Microinfusion Experimental Procedures}

For the experiment involving acute restraint stress and unilateral ICV infusion of alpha-helical CRF, rats were trained on the effort-discounting task until they displayed stable baseline levels of choice behavior for three consecutive days. Following recovery from surgery and retraining to stability, all cohorts of rats received a mock infusion prior to microinfusion test days. Here, the injector was placed into the guide cannula for the same duration as the infusion, however, no infusion was administered. Rats were then subjected to the first of four test days: (i) vehicle/no stress; (ii) vehicle/restraint stress; (iii) alpha-helical CRF/no stress, and; (iv) alpha-helical CRF/restraint stress. On test days, an infusion volume of $4 \mu \mathrm{l}$ was delivered over $3 \min 20 \mathrm{~s}$, via 30 -gauge injector that extended $0.8 \mathrm{~mm}$ past the end of the guide cannula. The injector was secured to tubing that was attached to a microsyringe pump. The injector was left in for an additional minute to ensure diffusion.

The no-stress and stress test days occurred as part of a 2-day sequence, with order of infusion type counterbalanced across rats. Thus, on the first day of the sequence, rats received infusions of vehicle or alpha-helical CRF, returned to their home cages for $10 \mathrm{~min}$ and placed in a quiet room for $1 \mathrm{~h}$ (no stress condition), prior to being placed in the operant chambers for testing. On the second day, rats received the same infusion as the previous day, returned to 
their home cage for $10 \mathrm{~min}$, after which the rats were restrained in a Plexiglas cylinder $(83 \times 133 \times 197 \mathrm{~mm}$; Harvard Apparatus, Massachusetts, USA) for $1 \mathrm{~h}$ located in the same room as the no-stress condition. A desktop fan was aimed at the restrainers and was used to reduce the risk of hyperthermia. The restrainer length was adjusted to keep the rat immobilized without causing pain. Following $1 \mathrm{~h}$ of restraint, the rats were placed back into their home cage where they remained undisturbed for $10 \mathrm{~min}$, followed by placement into the operant chamber for testing. Following this 2-day test sequence, rats were retrained to stability (approximately 5 days) and then experienced the counterbalanced infusion following the same protocol. Therefore, rats that previously received alpha-helical CRF now received vehicle infusions and vice versa.

For the ICV central CRF experiments, all squads of animals were trained to stability and underwent a mock infusion prior to testing (described above). The central CRF infusions were administered in either a $1 \mu$ l volume over $1 \mathrm{~min} 45 \mathrm{~s}$ or a $3 \mu \mathrm{l}$ volume over $3 \mathrm{~min} 34 \mathrm{~s}$. The injector was left in place for an additional $1 \mathrm{~min}$ to allow for diffusion. On the first day of a 2-day test sequence, rats received vehicle infusion and returned to their home cage for $10 \mathrm{~min}$ prior to behavioral testing. The following day, rats received a dose of CRF, followed by $10 \mathrm{~min}$ in their home cage prior to behavioral testing. For experiments involving counterbalanced infusions of multiple doses of CRF, after the first test sequence, rats were retrained until stable baseline behavior was attained (2-5 days) before receiving another test sequence of the counterbalanced infusions.

Experiments involving intra-VTA infusions were conducted in a similar manner. Once stability was achieved, rats underwent a mock infusion procedure, where two injectors were inserted into the bilateral guide cannula for the same duration as the infusion, however, there was no infusion administered. On test days, infusions were administered in a volume of $0.5 \mu \mathrm{l}$ over $1 \mathrm{~min} 15 \mathrm{~s}$. Following mock infusions, one group of rats received a bilateral vehicle infusion on the first day and another group received a CRF $(0.5 \mu \mathrm{g})$ infusion. Rats were returned to their home cage for $10 \mathrm{~min}$ prior to behavioral testing. Following 1-7 days of retraining, rats received a counterbalanced infusion of either vehicle or CRF.

\section{Histology}

Following testing, the rats were killed with $\mathrm{CO}_{2}$ and brains were removed and fixed in a $4 \%$ formalin solution. Brains were sectioned at $50 \mu \mathrm{m}$, mounted on gel-coated slides and Nissl-stained using Cresyl Violet. Photomicrographs of representative examples of an accurate and inaccurate placement in the lateral ventricle cannula are shown in Figure $1 \mathrm{a}$ and $\mathrm{b}$. Figure $1 \mathrm{c}$ represents accurate cannula placements in the VTA. Data from animals with placements that were either lateral or dorsal to the ventricle or the VTA were removed from the analyses.

\section{Data Analysis}

The main dependent variable obtained with the effortdiscounting task was the proportion of choices of the HR
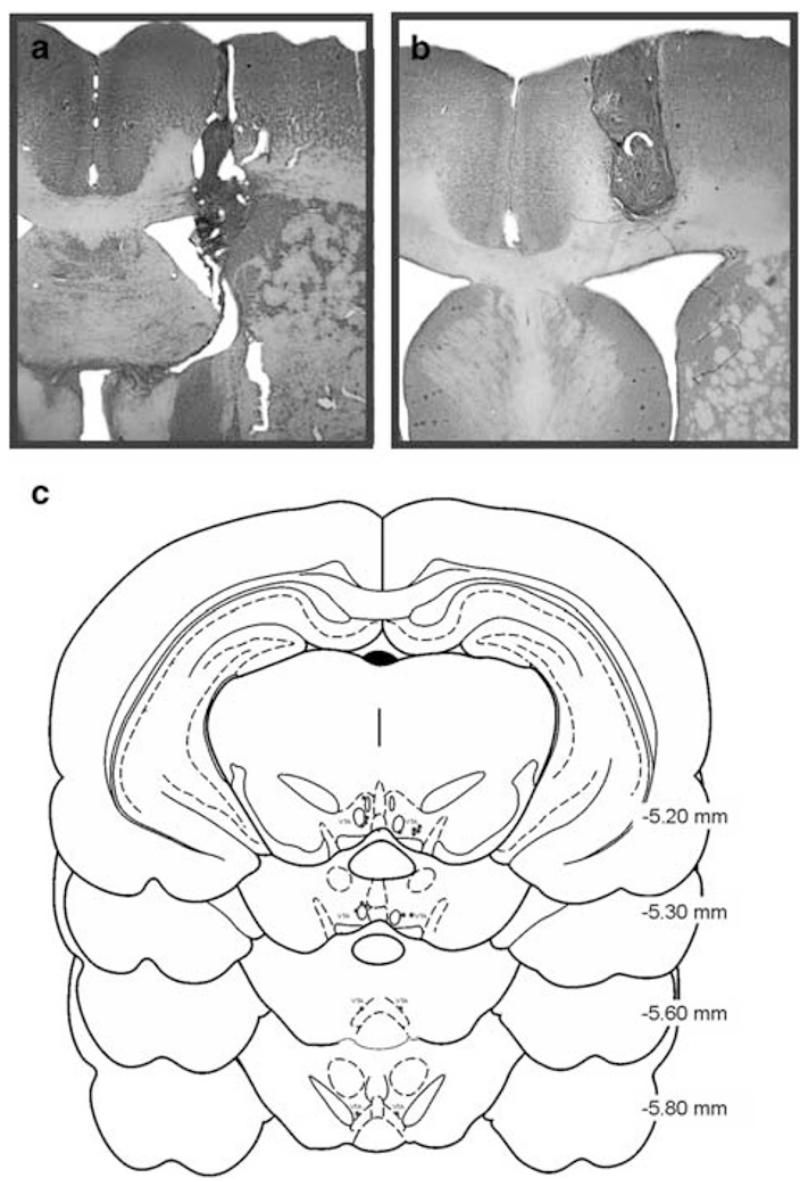

Figure I Histology. (a) Accurate unilateral lateral ventricle (ICV) cannula placement. (b) Missed unilateral lateral ventricle (ICV) cannula placement. (c) Representation of the accurate ventral tegmental area (VTA) cannula placements.

lever for each block, factoring in trial omissions. For this measure, the ratio of the number of HR choices divided by the total number of trials where a choice was made was calculated. Additional measures included rates of lever pressing on the HR lever, choice latency, and trial omissions. Choice data for the CRF antagonist experiment were analyzed using a 4 (treatment) $\times 4$ (block) repeated measures ANOVA. Choice data for intracranial CRF infusions experiments were analyzed with two-way repeated measures ANOVAs, with dose and block as the within-subjects factors. One- or two-way repeated measures ANOVA were used to analyze the other performance measures. Multiple comparisons using Dunnett's or Tukey's tests (http://onlinestatbook. com/2/calculators/studentized_range_dist.html) were used where appropriate.

For the progressive ratio experiment, the main dependent variables were the total number of lever presses and the breakpoint (the last ratio obtained); these were compared using one-way ANOVAs. Lever press rate was analyzed using a two-way within-subjects ANOVA, with Treatment and Ratio (the first four ratios, which all animals achieved after both treatments, as well as the rate during the last ratios achieved for each animal) as the within-subjects factors. 


\section{RESULTS}

\section{Alpha-helical CRF Ameliorates the Effect of Restraint Stress on Effort-Related Decision-making}

Our first experiment sought to replicate the effects of $1 \mathrm{~h}$ of acute restraint stress on effort-related choice and investigate whether central CRF activity mediates this redirection of preference behavior. Nineteen rats were tested on the effortdiscounting task, with the data from two animals removed because of missed placements (final $n=17$ ). Analysis of the choice data revealed a significant main effect of treatment $(\mathrm{F}(3,48)=2.81, p=0.05)$, but no significant treatment $\times$ block interaction $(\mathrm{F}(9,144)=1.23$, n.s. $)$. As shown in Figure $2 \mathrm{a}$ and b (left), acute stress caused a marked reduction in choice of the HR compared with the no stress conditions (Tukey's, $p<0.05)$. Moreover, under no stress conditions, performance after vehicle or alpha-helical CRF treatments was comparable ( $p>0.90$; Figure 2a, circles $v s$ triangles). However, of particular interest, preference for the HR option after alpha-helical CRF/stress treatments did not differ significantly from either vehicle/no-stress $(p>0.60)$ or alphahelical CRF/no-stress conditions $(p>0.90$, Figure $2 \mathrm{a}$ and $\mathrm{b}$, right), although in these post hoc analyses, the difference between the two stress conditions (vehicle $v s$ alpha-helical CRF) also was not statistically significant $(p<0.40)$. On the basis of the observation that acute stress alone significantly reduced preference for the $\mathrm{HR}$ option relative to the corresponding no-stress condition, whereas stress+alphahelical CRF did not, we interpret these data to imply that the effects of acute stress on effort-discounting were attenuated by CRF antagonism.

After vehicle infusions, restraint stress increases choice latency relative to the no-stress conditions $(\mathrm{t}(16)=2.46$, $p<0.05)$, however, the overall analysis of these data did not reveal any significant differences across the different conditions on this measure (main effect of treatment: $\mathrm{F}(348)=2.33$, $p=0.086$; treatment $\times$ block interaction $\mathrm{F}(9,144)=0.68$, n.s. Figure 2c). Likewise, there were no differences between treatments in terms of rates of lever pressing on the HR lever $(\mathrm{F}(3,48)=0.67$, n.s.; Figure $2 \mathrm{~d})$ or trial omissions $(\mathrm{F}(3,48)=$ 1.34 , n.s.; range of the group means $=0.4-5.3$ ). Collectively, these results indicate that acute stress reduces preference for the high effort/high reward, redirecting choice biases towards low effort/low reward options. However, this effect was attenuated by prior administration of a CRF antagonist, suggesting that the ability of acute stress to reduce the tendency to work harder to obtain a larger reward is driven, at least in part, by an increase in central CRF transmission.

\section{Central CRF Infusion Mimics Acute Stress on Effort-Related Choice}

After uncovering a key role for CRF in mediating the effects of stress on cost/benefit decision-making, we next investigated whether central CRF administration could mimic the effect of acute stress on effort-discounting. We tested the effects of three doses of CRF $(0.25,1$, and $3 \mu \mathrm{g})$ dissolved in either $1 \mu \mathrm{l}$ or $3 \mu \mathrm{l}$ of artificial cerebrospinal fluid in 17 rats. Data from four of these rats were removed from the analyses because of missed cannula placements (final $n=13$ ). Performance after 1 vs $3 \mu$ linfusions of vehicle did not differ $(F(2,24)=1.19$, n.s.), so the data from all three vehicle
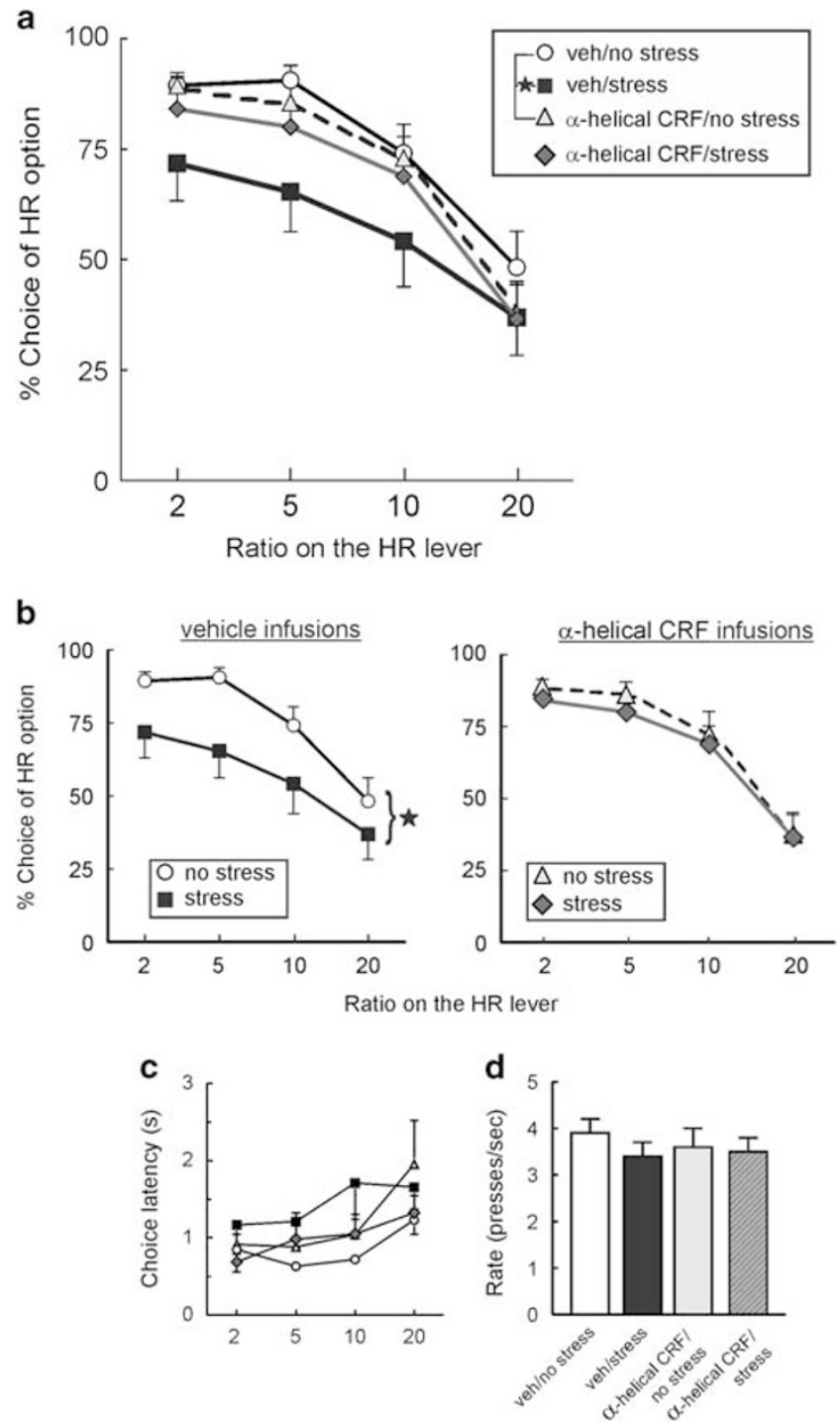

Figure 2 CRF receptor antagonism blocks the effects of acute restraint stress on effort discounting. (a) The ordinate shows the percent choice of the HR lever across the four trial blocks and the abscissa indicates the four trial blocks with increasing effort ratio. One hour restraint after ICV vehicle infusion decreased the selection of the HR option across all trial blocks relative to vehicle/no-stress conditions (stars denote $p<0.05$, Tukey's tests). However, infusion of alpha-helical CRF attenuated stress-induced reduction in preference for the HR option. (b) Same data as in (a), plotted for clarity to highlight the stress-induced reduction in choice of the HR option after vehicle infusions (left) and the relative lack of effect of restraint on choice after treatment with alpha-helical CRF (right). (c) Choice latency across the four treatment conditions and four trial blocks. (d) Rates of pressing on the HR lever did not differ across the different treatment conditions.

infusion days were combined for the analysis. Analysis of the choice data revealed a significant main effect of treatment $(\mathrm{F}(3,36)=8.36, p<0.001$; treatment $\times$ block interaction $(\mathrm{F}(9,108)=1.37$, n.s.; Figure 3a). Multiple comparisons using Dunnett's tests confirmed that the $0.25 \mu \mathrm{g}$ or $1 \mu \mathrm{g}$ doses did not alter choice relative to vehicle. However, the higher CRF dose $(3 \mu \mathrm{g})$ significantly reduced choice of the HR option $(p<0.01)$. With respect to other performance measures, the $3 \mu \mathrm{g}$ dose of CRF increased choice latency across all trial blocks of trials (main effect of treatment: $\mathrm{F}(3,36)=4.79$, 

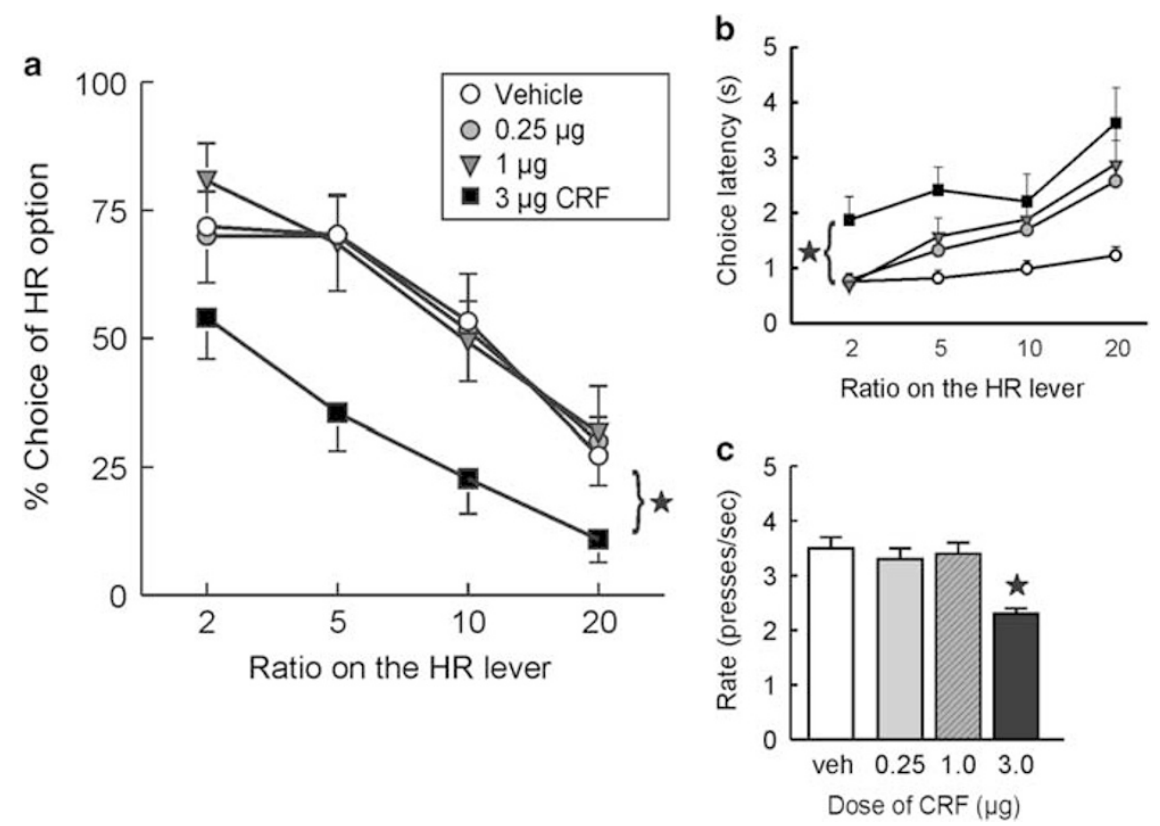

Figure 3 Central CRF infusion mimics the effect of acute restraint stress on effort discounting. (a) ICV Infusions of a $3 \mu \mathrm{g}$ dose of CRF reduced preference of the HR option compared with vehicle infusion, whereas the two lower doses of CRF had no effect on choice behavior (0.25 and I $\mu \mathrm{g})$. (b) The $3 \mu \mathrm{g}$ dose of $\mathrm{CRF}$ increased choice latency compared with vehicle infusion across all four blocks of trials. (c) Rates of lever pressing on the HR lever were also reduced following the $3 \mu \mathrm{g}$ CRF dose. Stars denote $p<0.05$ vs vehicle.

$p<0.01$ and Dunnett's, $p<0.01$; treatment $\times$ block interaction: $F(9,108)=1.43$, n.s.; Figure $3 b$ ) and reduced rates of lever pressing $(\mathrm{F}(3,36)=30.95, p<0.001$, and Dunnett's $p<0.05$, Figure $3 \mathrm{c}$ ). The $3 \mu \mathrm{g}$ dose also increased trial omissions $(9.7+/-2.8)$ relative to vehicle $(1.0+/-0.6)$, whereas the other two doses did not $(0.25 \mu \mathrm{g}=0.1+/ 0.1$; $1.0 \mu \mathrm{g}=0.4+/-0.2 ; \mathrm{F}(3,36)=10.15, p<0.001$ and Dunnett's, $p<0.05)$. Together, these data suggest that the administration of exogenous CRF reduces preference for animals to work harder to obtain larger rewards, increases latency to make a choice, and also reduces response vigor.

\section{Central CRF Infusion Does Not Disrupt Reward Magnitude Discrimination}

To further clarify the manner in which increased CRF activity affects decision-making, we conducted a control experiment using a reward magnitude discrimination to determine whether these treatments induced a more fundamental deficit in preference for larger $v s$ smaller rewards. A separate group of nine rats were trained on a simpler decision-making task which equated the costs of the two levers, so that a single press on the HR or LR lever delivered four or two reward pellets, respectively. As shown in Figure $4 \mathrm{a}, \mathrm{ICV}$ infusion of $3 \mu \mathrm{g}$ CRF did not significantly alter decision-making on this simpler task $(F(1,8)=0.86$, n.s.). Interestingly, these treatments did significantly increase choice latencies (main effect of treatment: $F(1,8)=$ $8.76, p<0.05$; treatment $\times$ block interaction: $\mathrm{F}(3,24)=2.50$, $p=0.08$; Figure $4 \mathrm{~b}$ ) in a manner similar to the effects of restraint on performance of this task (Shafiei et al, 2012). However, trial omissions were unaffected (vehicle $=0$; $\mathrm{CRF}=1.4+/-0.8 ; \mathrm{t}(8)=1.77$, n.s.). Thus, increasing central CRF activity does not affect preference for larger $v s$ smaller rewards of equal cost, nor does it disrupt spatial discrimination abilities. However, as was observed in the effortdiscounting experiment, these treatments did increase latencies to initiate actions that would yield reward.

\section{Central CRF Infusion and Instrumental Responding on a Progressive Ratio Schedule}

Increasing central CRF activity did not alter the subjective value of objectively larger rewards. However, the possibility remained that increased CRF activity may have interfered with the motivation to exert greater amounts of effort to obtain a reward. To address this, we tested the effects of CRF infusion on instrumental responding for food delivered on a progressive ratio schedule of reinforcement, a common assay of motivation in rodents. In well-trained rats $(n=8)$, ICV administration of CRF $(3 \mu \mathrm{g})$ reduced total number of lever presses $(\mathrm{F}(1,7)=17.86, p<0.01$; Figure $4 \mathrm{c})$ and the breakpoint (or last ratio achieved; $\mathrm{F}(1,7)=19.60, \quad p<0.01$; Figure $4 \mathrm{~d}$ ) relative to performance after vehicle.

To analyze the rates of lever pressing, we accommodated for the fact that most rats achieved a lower breakpoint after CRF infusions relative to control treatments. As such, we analyzed the rate according to the ratio completed for all rats under both conditions (vehicle and CRF infusion), which in this instance, was the fourth ratio (six presses required), as well as the pressing rate for the last ratio obtained. CRF infusions reduced rates of responding (main effect of treatment: $\mathrm{F}(1,7)=13.38, p<0.01$; treatment $\times$ ratio interaction: $F(4,28)=12.68, \quad p<0.001)$. Simple main effects analysis revealed that rats displayed comparable rates of lever pressing for the first two ratios of the session, but during the later ratios, rates of responding were slower following CRF treatments relative to vehicle $(p<0.05$; 

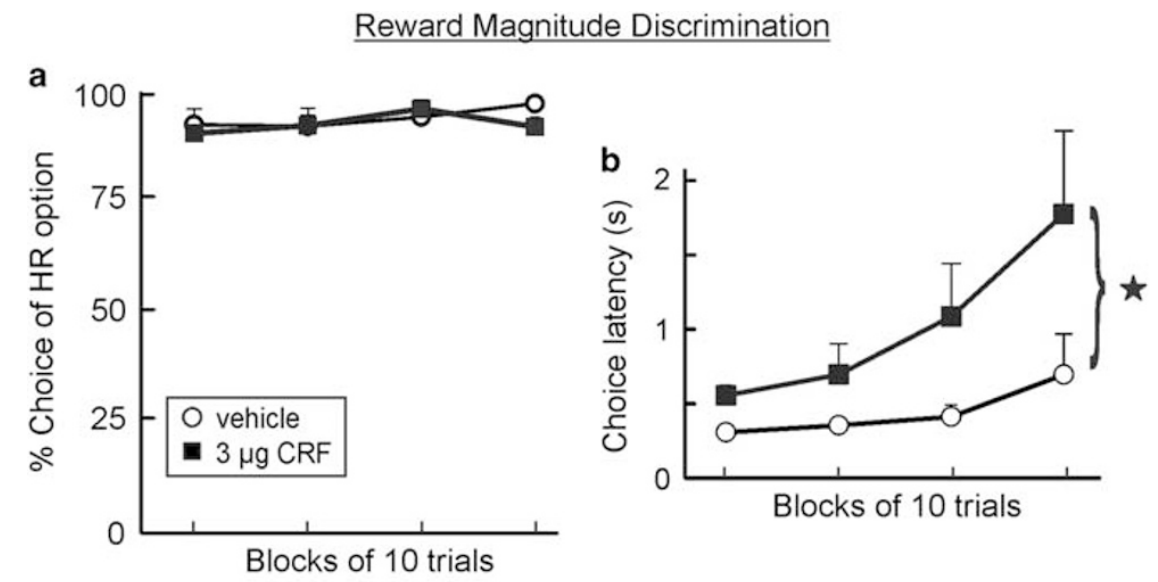

Progressive Ratio
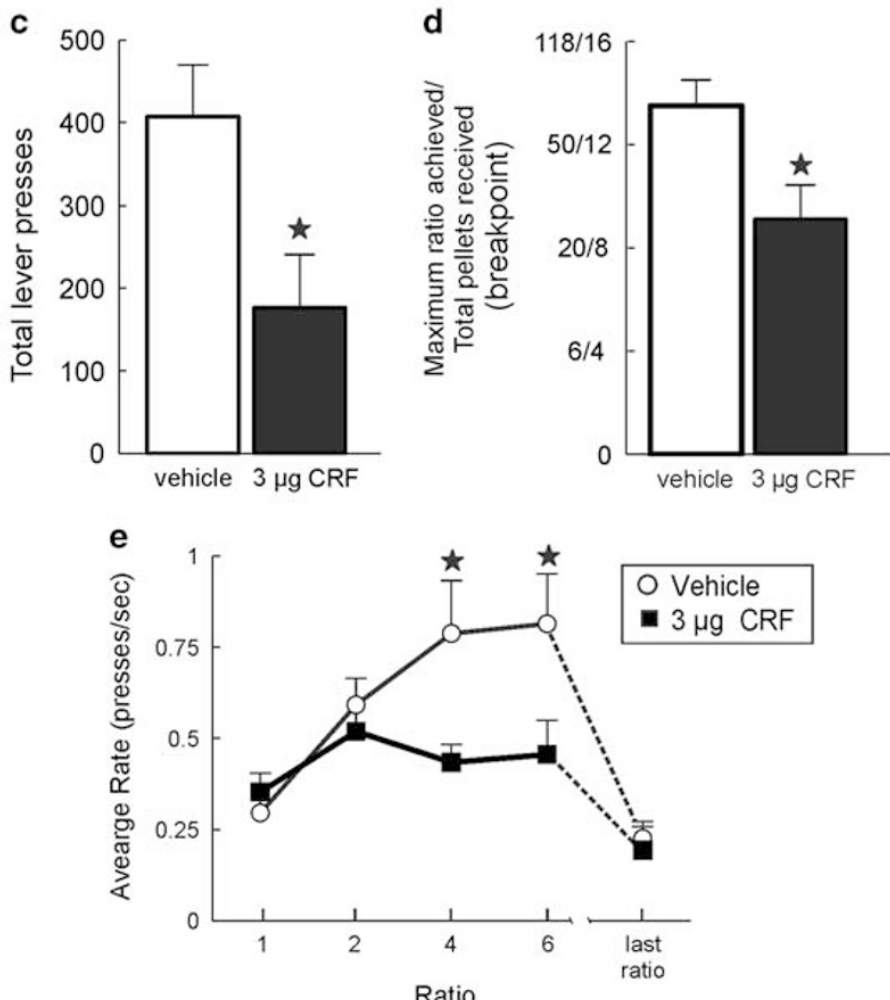

Figure 4 Central CRF infusion does not affect reward magnitude discrimination but diminishes motivation to work for reward in a progressive ratio schedule of reinforcement. (a) CRF did not alter preference for the larger vs smaller rewards during a reward magnitude discrimination when there was no additional cost associated with it. (b) Response latencies averaged across the four trial blocks. CRF infusion increased the latency to make a choice. (c) ICV CRF infusion $(3 \mu \mathrm{g})$ reduced the total number of lever presses completed during the progressive ratio task compared to vehicle infusion. (d) CRF ( $3 \mu \mathrm{g}$ ) infusion reduced the breakpoint/total number of reward pellets obtained during the session. (e) The number of presses/s (rate) for the first four ratios and the last ratio obtained. CRF infusion had no effect on rate during the lower ratios or the last ratio obtained, however, CRF reduced the pressing rate during the higher ratios. Stars denote $p<0.05$.

Figure 4e). Note that in the effort-discounting experiment, this same dose of CRF caused both a reduction in rates of lever pressing as well as an increase in latencies to initiate a response. Thus, it is possible that the effects of CRF on average response rates in the progressive ratio experiment may have also be driven in part by an increase in the latency to reinitialize responding after consumption of a food pellet. Collectively, these data indicate that CRF infusions reduces motivation to respond at high ratios to obtain food reward.

\section{Intra-VTA CRF Infusion and Effort Discounting}

Our findings that ICV infusions of CRF shifts choice biases away from high-effort/high reward options prompted us to explore the potential brain nuclei where CRF may be acting to mediate these effects. To this end, we targeted the dopamine cell body region in the VTA as (i) the VTA expresses CRF receptors (Van Pett et al, 2000), (ii) CRF is released into the VTA during episodes of acute stress (Wang et al, 2005), 

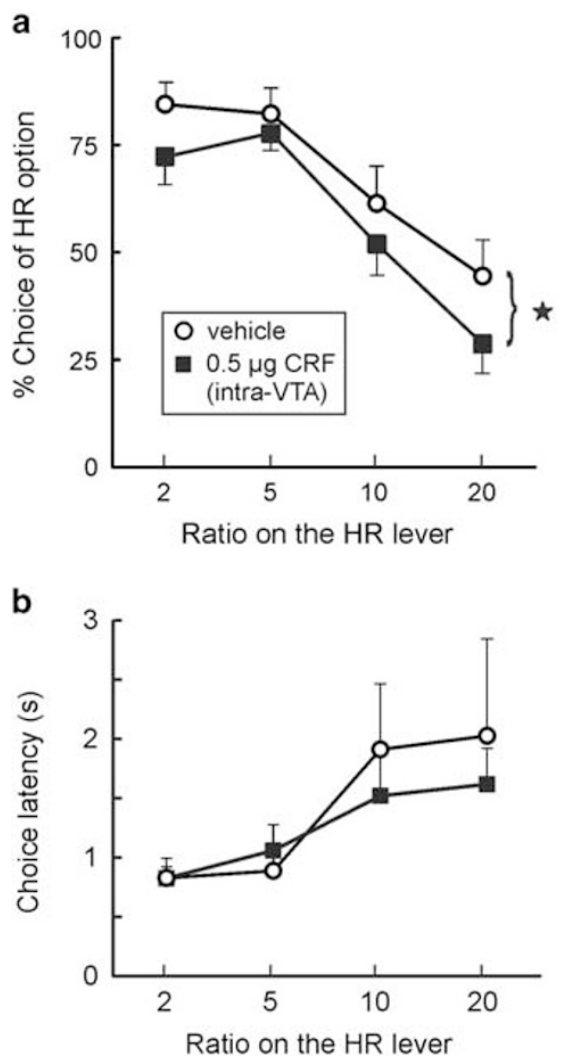

Figure 5 Intra-VTA CRF infusion mimics effect of acute restraint stress and central CRF infusion on effort discounting. (a) Intra-VTA CRF $(0.5 \mu \mathrm{g})$ infusion reduced preference for the HR option compared with vehicle infusion. (b) Choice latencies across the four trial blocks. There was no effect of intra-VTA CRF on choice latency. (c) Rates of responding on the HR lever averaged across all four blocks. Intra-VTA CRF caused a slight but nonsignificant effect on response vigor rate. Stars denote $p<0.05$.

and (iii) dopamine has a critical role in promoting choice of larger, high cost rewards (Salamone et al, 1991; Sokolowski and Salamone, 1998; Aberman and Salamone, 1999; Salamone et al, 1994; Cousins and Salamone, 1994; Floresco et al, 2008). Eleven rats were trained and tested on the effort-discounting task; two were removed owing to cannula placements outside the VTA (final $n=9$ ). IntraVTA administration of CRF $(0.5 \mu \mathrm{g})$ significantly reduced choice of the HR option compared with vehicle infusion $(\mathrm{F}(1,8)=7.56, p<0.05 ;$ Figure 5a). Interestingly, these treatments did not affect choice latency (main effect of treatment: $\mathrm{F}(1,8)=0.32$, n.s.; treatment $\times$ block interaction: $\mathrm{F}(3,24)=0.51$, n.s.; Figure $5 \mathrm{~b}$ ) or trial omissions (vehicle $=$ $0.1+/-0.1 ; \mathrm{CRF}=1.1+/-0.2 ; \mathrm{F}(1,8)=2.17$, n.s.). Intra-VTA CRF treatments did cause a slight reduction in the rates of lever pressing as was observed following ICV administration of this compound, but analysis of these data only revealed an effect that approached statistical significance $(\mathrm{F}(1,8)=4.57$, $p=0.07$; Figure $5 c$ ).

\section{DISCUSSION}

The present series of experiments provides strong evidence that CRF mediates stress-induced alterations in effort-related decision-making. One hour of restraint stress reduced preference for the larger, costlier reward, but this effect was attenuated by prior administration of the CRF antagonist, alpha-helical CRF. Furthermore, central administration of CRF itself reduced preference for larger, costlier rewards, but did not affect preference for larger $v s$ smaller rewards of equal costs. On the other hand, CRF administration did reduce the motivation to work for reward, as evidenced by reduced responding for reward delivered on a progressive ratio schedule. Finally, alterations in evaluating subjective effort costs appear to involve CRF acting in the VTA as CRF infusion into this nucleus recapitulated the choice behavior profile elicited by both acute restraint stress and central CRF infusion.

\section{Stress, Cost/benefit Decision-making and CRF}

Previous work from our laboratory revealed that $1 \mathrm{~h}$ of restraint stress markedly reduced preference for larger rewards associated with a greater effort cost (Shafiei et al, 2012). It is well established that this form of acute stress increases circulating corticosterone levels and also enhances dopamine efflux in regions such as the prefrontal cortex and amygdala (Imperato et al, 1991; Jackson and Moghaddam, 2004; Del Arco et al, 2015). However, in attempting to elucidate the neurochemical mechanisms underlying this effect, we found that systemic treatment with corticosterone at doses yielding plasma levels comparable with those induced by stress failed to recapitulate this effect. Similarly, stress-induced perturbations on choice behavior did not appear to be driven by increased dopamine transmission, as pretreatment with the dopamine antagonist flupenthixol failed to block the effect of acute stress on this measure (Shafiei et al, 2012). We now reveal that CRF transmission has a fundamental role in mediating the stress-induced alterations in effort choice preference, as pretreating rats with the CRF antagonist, alpha-helical CRF, markedly attenuated the effect of restraint stress, while this drug had no effect on behavior on its own.

The above-mentioned findings were complemented by a subsequent experiment investigating whether the administration of exogenous CRF was sufficient to reorganize effortrelated decision-making in a manner similar to restraint stress. High $(3 \mu \mathrm{g})$, but not lower $(0.25 \mu \mathrm{g}$ or $1 \mu \mathrm{g})$, doses of $\mathrm{CRF}$ into the lateral ventricle significantly reduced preference for the HR option during effort discounting. This dose/ response effect differs somewhat from previous studies reporting that lower doses of CRF can alter behavior on a variety of anxiety-related assays (Campbell et al, 2004; Dunn and Berridge, 1990). The fact that only the $3 \mu \mathrm{g}$ dose was effective here suggests that more complex forms of behavior may only be susceptible to more robust increases in circulating CRF, compared with relatively simpler or spontaneous behaviors related to anxiety, despair, or social investigation. Collectively, these results indicate that CRF, in the context of acute stress, influences the subjective evaluation during effort-related decision-making, modifying subjective choice biases towards lower cost yet smaller rewards.

Increasing central CRF transmission activates the HPA axis and promotes the release of corticosterone. In turn, increased corticosterone can act centrally to modulate various forms of learning and cognition. This being said, 
we find it unlikely that the effects of CRF treatments on decision-making were mediated by increased corticosterone release. As discussed above, administration of exogenous corticosterone failed to affect effort discounting (Shafiei et al, 2012). Furthermore, previous studies have shown that a wide range of doses of centrally infused CRF $(0.1-10 \mu \mathrm{g})$ activates the HPA axis and increases plasma corticosterone levels to a similar degree (Campbell et al, 2004; Cador et al, 1992). In comparison, only the $3 \mu \mathrm{g}$ dose of CRF altered choice behavior in the present study, whereas treatment with the lower dose that would also be expected to increase plasma corticosterone levels had no effect. Thus, it is more likely that mechanisms underlying these effects of increased CRF transmission are independent of its effects on HPA axis activation and increases in plasma corticosterone levels.

\section{Cognitive/Motivational Alterations Induced by Increased CRF Activity}

Numerous cognitive and/or motivational processes may be affected by increased CRF activity, which could bias choice away from the larger, costlier reward. For example, these treatments may have altered processes related to the objective valuation of different rewards and caused a more general impairment in preference for larger $v s$ smaller rewards, as has been observed following inactivation of the nucleus accumbens shell or reducing GABA transmission in the prefrontal cortex (Stopper and Floresco, 2011; Piantadosi et al, 2016). To address this, we utilized a reward magnitude discrimination, equating the cost of the two lever options. Here, central CRF infusion had no effect on choice of objectively larger rewards, a null result similar to that observed following acute restraint stress (Shafiei et al, 2012). This lack of effect also indicates that alterations in behavior induced by CRF infusions are unlikely to be due to changes in satiety (Stopper and Floresco, 2014) or other non-specific impairments. Thus, more fundamental reward processes that bias choice towards larger vs smaller rewards are relatively unaffected by increased CRF activity.

On the other hand, increased CRF activity may have altered the subjective evaluation of effort costs and interfered with the motivation to work for reward or the willingness to respond at high ratios. To address this possibility, we tested how CRF administration affected responding for reward delivered on a progressive ratio schedule. Here, central CRF infusion significantly reduced the motivation to work for reward. Juxtaposition of these findings with the data from the effort-discounting experiments suggest that increased CRF activity perturbs motivational processes that promote sustained patterns of behavior required to overcome effort costs that separate an organism from its desired rewards. In keeping with this idea, CRF infusions also reduced the rates of lever pressing across the different tasks, particularly when the response requirements were high, presumably owing to an increased tendency to disengage from the lever for periods of time and/or re-engage responding. Thus, rather than reducing the incentive value of larger rewards, increased CRF transmission appears to amplify the perceived effort costs that may be required to obtain them. Alternatively, it could be argued that CRF or acute stress may be impairing numerous aspects of motivation non-discriminately, which in turn, alter both effort-related decision-making and progressive ratio responding. However, it is unlikely that this would explain the whole behavioral profile detailed in this study. Were this the case, the expectation would be that these manipulations would alter behavior on any task that required goal-directed behavior, including reward magnitude discrimination. Yet, unlike other manipulations that cause more generalized reductions in motivation (eg, prefeeding before a test session (Stopper and Floresco, 2014)), CRF treatment or stress did not alter preference for larger $v s$ smaller rewards of equal cost (Shafiei et al, 2012). As such, we believe it is more likely that these manipulations somewhat more selectively altered motivational processes involved in invigorating behavior and enabling an organism to exert greater effort to obtain a goal.

It bears mentioning that although CRF infusions and $1 \mathrm{~h}$ of restraint stress induced comparable alterations in effortrelated decision-making, in our hands, similar restraint stress did not alter responding for food delivered on progressive ratio schedule (Shafiei et al, 2012). In this regard, different types of stressors have been reported to induce variable effects on progressive ratio responding. Wanat et al (2013) reported that $20 \mathrm{~min}$ of restraint stress combined with intraVTA vehicle infusions reduced breakpoints relative to baseline responding using a two-lever task where the active lever shifted between sessions and the reinforcement schedule was more liberal than that used here. In contrast, treatment with the pharmacological stressor yohimbine increased breakpoints and this effect was attenuated by a $\mathrm{CRF}_{1}$ antagonist (Liu, 2015). It is interesting to note that chronic corticosterone exposure significantly reduces the breakpoint and number of lever presses in a progressive ratio task in a manner similar to central CRF infusion reported here (Olausson et al, 2013). Thus, the dose of CRF that was effective in the present study may be more analogous to changes in CRF activity induced by more intense or chronic stress manipulations compared with $1 \mathrm{~h}$ of restraint.

In addition to affecting choice behavior and response rates, $\mathrm{CRF}$ infusions also induced reliable increases in decision latencies, paralleling effects of acute restraint stress reported previously (Shafiei et al, 2012). Increased deliberation times after either CRF infusions or acute stress were apparent not only during more complex decisions involving evaluations of effort costs, but also during a relatively simpler reward magnitude discrimination. In this latter instance, these manipulations did not affect choice behavior, suggesting that the mechanisms through which increased CRF transmission alters choice latencies may be dissociable from those involved in biasing the direction of choice. Notably central CRF infusions have been reported to increase choice latencies during tests of attention (Van't Veer et al, 2012; Beard et al, 2015). These findings suggest that the ability of acute stress to induce 'indecisiveness' and increase processing times for action selection is also mediated in part by increased central CRF transmission.

\section{CRF Actions in the VTA and Effort-related Decision-making}

In a final experiment, we sought to identify neural loci where CRF may be acting to alter motivation within the context of effort-related decision-making. To this end, we targeted the midbrain dopamine neurons in the VTA, given the 
well-established role that dopamine has in promoting preference of the larger, costlier rewards (Salamone et al, 1991; Sokolowski and Salamone, 1998; Salamone et al, 1994; Cousins and Salamone, 1994; Denk et al, 2005; Floresco et al, 2008). CRF is released in the VTA during episodes of acute stress (Wang et al, 2005) and previous findings suggest that stress-induced perturbations in motivation are mediated by the activation of CRF receptors within the VTA (Wanat et al, 2013). Intra-VTA CRF reduces the breakpoint on a progressive ratio task in a manner similar to the effects of ICV CRF infusions in the present study, and blockade of VTA CRF receptors ameliorated the motivational deficits induced by acute stress (Wanat et al, 2013). In keeping with the above-mentioned findings, we found that CRF infusion into the VTA significantly reduced preference for the larger, costlier reward in the effort-discounting task. The fact that acute restraint stress, ICV, or intra-VTA CRF infusion all elicited a similar effect on effort-related choice provides strong evidence that increased CRF release triggered by stressful events may act within the VTA to modulate cost/ benefit decision-making.

The question remains as to how CRF may modulate VTA dopamine neuron activity to alter decision-making. CRF, originating from outside sources including the bed nucleus of the stria terminalis (Rodaros et al, 2007; Vranjkovic et al, 2014) or within the VTA itself (Grieder et al, 2014), acts in complex, often opposing ways and can increase or decrease excitatory and/or inhibitory transmission in the VTA through numerous mechanisms. In vitro studies have revealed that $\mathrm{CRF}_{1}$ receptors act presynaptically on glutamatergic terminals to increase glutamatergic drive onto dopamine neurons (Williams et al, 2014), as well as exerting postsynaptic actions to increase EPSCs and firing rates of dopamine neurons (Wanat et al, 2008). $\mathrm{CRF}_{2}$ receptors, in conjunction with CRF-binding protein may also facilitate NMDAR-mediated synaptic transmission on dopamine neurons (Ungless et al, 2003). These findings compliment reports suggesting that increased CRF activity can promote terminal dopamine release (Lavicky and Dunn, 1993; Holly et al, 2015). In contrast, there is evidence to suggest that activation of VTA $\mathrm{CRF}_{2}$ receptors can increase GABA release that acts both on postsynaptic GABA-A receptors and presynaptic GABA-B heteroreceptors located on glutamate terminals to attenuate glutamate release (Williams et al, 2014). This latter effect would be expected to reduce dopamine neuron firing. Collectively, these studies highlight the complexity with which different CRF receptors act in order to shape VTA neuronal excitability.

Although further studies are needed to clarify the precise mechanisms through which CRF modulates VTA dopamine neuron activity, the fact remains that ICV or intra-VTA infusions of CRF alter effort-related decision-making in a manner similar to dopamine antagonism, either systemically or in the nucleus accumbens (Salamone et al, 1991, 1994; Floresco et al, 2008; Nowend et al, 2001; Farrar et al, 2010). This resemblance would suggest that despite the complex actions of CRF in the VTA, the net effect of enhanced CRF transmission in these situations may be to reduce mesoaccumbens dopamine activity. In support of this notion, intra-VTA CRF infusion attenuated nucleus accumbens dopamine release evoked by rewards delivered on a progressive ratio schedule, while leaving phasic dopamine responses to reward-predictive cues unaffected, highlighting how activation of VTA CRF receptors in the behaving animal can alter mesoaccumbens dopamine release in a stimulusspecific manner (Wanat et al, 2013). Conversely, a recent report by Twining et al (2015) showed that reductions in nucleus accumbens dopamine transmission induced by an aversive tastant was reversed by administration of a CRF antagonist into the VTA. Similarly, ICV administration of a $\mathrm{CRF}_{1}$ antagonist increases dopamine neuron population activity and mesoaccumbens dopamine release, 'suggestive of a tonic inhibitory role for CRF on the activity of VTA dopamine neurons' (Lodge and Grace, 2005). Collectively, these previous findings suggest that CRF in the VTA can at least in some instances act in a stimulus-specific manner to attenuate dopamine release, putatively by reducing glutamate and/or enhancing GABA release onto dopamine neurons in the VTA. With respect to the present study, CRF infusions may have dampened dopamine release triggered by receipt of rewards. Notably, suppression of reward-associated dopamine signaling by stimulation of the lateral habenula also reduced choice of larger, uncertain rewards (Stopper et al, 2014). A similar mechanism may explain the results of the present study, wherein increased CRF activity in the VTA could blunt reward-associated dopamine signaling and reduce the perceived value of rewards relative to the effort costs required to obtain them. This in turn may reduce the tendency to select the more costly options on subsequent choices.

Although intra-VTA CRF infusions altered choice behavior, these manipulations did not increase choice latencies, standing in contrast to the effects induced by either ICV CRF or acute stress. The timing and effective doses of CRF in these experiments may account for these discrepancies. For instance, central infusions of exogenous CRF were administered as a bolus, $10 \mathrm{~min}$ prior to behavioral testing. In comparison, acute restraint stress used here would be expected to result in a slower accumulation of CRF within the VTA and other target nuclei. On the other hand, it is important to note that stress-induced increases in choice times appear to be mediated by enhanced dopamine transmission, as this effect was blocked by the administration of a dopamine antagonist prior to stress exposure (Shafiei et al, 2012). Although the terminal region(s) where increased dopamine may mediate this effect is unclear, stimulation of $\mathrm{D}_{2}$ receptors in the prefrontal cortex or basolateral amygdala increases choice latencies during other types of cost/benefit decision-making (St. Onge et al, 2011; Larkin et al, 2015). It is interesting to note that acute stress potentiates DOPAC metabolism and extracellular dopamine levels in the nucleus accumbens and prefrontal cortex (Abercrombie et al, 1989; Dunn and Berridge, 1990; Holly et al, 2015; Imperato et al, 1991; Matsuzaki et al, 1989) in a manner similar to ICV CRF infusion (0.2-20 $\mu \mathrm{g}$; Dunn, 1988; Dunn and Berridge, 1987). However, intra-VTA CRF infusions reduce dopamine metabolism in the PFC and increases DA metabolism in the NAc 60 min following infusion (Kalivas et al, 1987). In addition, intra-accumbens CRF infusion (0.1 and $1 \mu \mathrm{g})$ acts locally to enhance dopamine release (Lemos et al, 2012). This suggests that CRF may have contradictory effects on dopamine transmission depending on the neural loci involved. Furthermore, CRF infusion may exert a biphasic effect on DA transmission depending on the region where it 
may be acting. It therefore seems reasonable to propose that stress-induced increases in CRF transmission may retard decision-processing times by enhancing terminal dopamine release via mechanisms independent of its actions within the VTA. As such, the spectrum of behavioral alterations induced by increased CRF activity (eg, altered choice behavior vs latencies to make these choices) appear to be anatomically dissociable, further highlighting how CRF may act in a circuit-specific manner to modulate different aspects of motivated behavior.

\section{Summary and Clinical Implications}

The results of the present study provide novel insight into the neural mechanisms through which acute stress may alter cost/benefit decision-making and motivational processes, identifying a key role for increased CRF transmission in mediating its effects on decision biases, choice latencies, and response vigor. In addition, these results may also have important implications for understanding the pathophysiology that drives certain symptoms of stress-related psychiatric illnesses, particularly major depressive disorder. Negative affect and depressed mood are the most recognized phenotypes of depression. However, individuals with this disorder also suffer from a number of energy-related deficiencies, including a substantial lack of motivation, or anergia, with depressed patients reluctant to expend effort in exchange for pleasurable experiences (Tylee et al, 1999; Stahl, 2002). Indeed, it is this lack of motivation, and not an inability to experience pleasure per se, that is the most debilitating symptom of depression, rendering sufferers unable to participate in everyday activities (Salamone et al, 2015). With this in mind, depressed patients tested on a back-translated assay of effort-based decision-making show a marked reduction in preference for larger rewards associated with greater effort costs (Treadway et al, 2012) and increased decision latencies on various tests of executive functioning (Rubinsztein et al, 2000; Murphy et al, 2001). These deficits are remarkably similar to the effects of acute restraint stress or CRF infusions reported here. Given that abnormal increases in central CRF activity have been implicated in the pathophysiology of depression (Nemeroff et al, 1984; Banki et al, 1987; Hauger et al, 2009; Binder and Nemeroff, 2009), the present findings provide support for the notion that aberrant hyperactive CRF transmission may be a key driving force underlying the decline in motivation seen in human depression, potentially via its effects on dopamine transmission. As such, development of compounds that can attenuate CRF activity and in particular, its effects on the dopamine system, may hold promise for treating motivational deficits associated with depression and other stressrelated psychiatric disorders.

\section{FUNDING AND DISCLOSURE}

The authors declare no conflict of interest.

\section{ACKNOWLEDGMENTS}

SBF has received funds to conduct contract work for Pfizer Inc. The work supported by this grant is not related to the findings presented in this article. This research was supported by grants from the Canadian Institutes of Health Research to SBF (MOP 102478). CAB is the recipient of a University of British Columbia Graduate Fellowship.

\section{REFERENCES}

Abercrombie ED, Keefe KA, DiFrischia DS, Zigmond MJ (1989). Differential effect of stress on in vivo dopamine release in striatum, nucleus accumbens, and medial frontal cortex. I Neurochem 52: $1655-1658$.

Aberman JE, Salamone JD (1999). Nucleus accumbens dopamine depletions make rats more sensitive to high ratio requirements but do not impair primary food reinforcement. Neuroscience 92: 545-552.

Adamec RE, McKay D (1993). The effects of CRF and $\alpha$-helical CRF on anxiety in normal and hypophysectomized rats. J Psychopharm 7: $346-354$.

Arnsten AF (2009). Stress signalling pathways that impair prefrontal cortex structure and function. Nat Rev Neurosci 10: $410-422$.

Arnsten AF, Goldman-Rakic PS (1998). Noise stress impairs prefrontal cortical cognitive function in monkeys: evidence for a hyperdopaminergic mechanism. Arch Gen Psychiatry 55: 362-368.

Banki CM, Bissette G, Arato M, O'Connor L, Nemeroff CB (1987). CSF corticotropin-releasing factor-like immunoreactivity in depression and schizophrenia. Am J Psychiatry 144: 873-877.

Beard C, Donahue RJ, Dillon DG, Van't Veer A, Webber C, Lee J et al (2015). Abnormal error processing in depressive states: A translational examination in humans and rats. Transl Psychiatry 5: e564.

Berridge CW, Dunn AJ (1989). Restraint-stress-induced changes in exploratory behavior appear to be mediated by norepinephrinestimulated release of CRF. J Neurosci 9: 3513-3521.

Binder EB, Nemeroff CB (2009). The CRF system, stress, depression and anxiety - insights from human genetics studies. Mol Psychiatry 15: $574-588$.

Bittencourt JC, Sawchenko PE (2000). Do centrally administered neuropeptides access cognate receptors?: An analysis in the central corticotropin-releasing factor system. J Comp Neurol 20: 1142-1156.

Brown G, Jackson A, Stephens DN (1998). Effects of repeated withdrawal from chronic ethanol on oral self-administration of ethanol on a progressive ratio schedule. Behav Pharm 9: 149-161.

Bryce CA, Howland JG (2015). Stress facilitates late reversal learning using a touchscreen-based visual discrimination procedure in male Long Evans rats. Behav Brain Res 278: 21-28.

Butts KA, Floresco SB, Phillips AG (2013). Acute stress impairs setshifting but not reversal learning. Behav Brain Res 252: 222-229.

Butts KA, Weinberg J, Young AH, Phillips AG. (2011). Glucocorticoid receptors in the prefrontal cortex regulate stress-evoked dopamine efflux and aspects of executive function. Proc Nat Acad Sci USA 108: 18459-18464.

Cador M, Ahmed SH, Koob GF, Le Moal M, Stinus L (1992). Corticotropin-releasing factor induces a place aversion independent of its neuroendocrine role. Brain Res 597: 304-309.

Campbell BM, Morrison JL, Walker EL, Merchant KM (2004). Differential regulation of behavioral, genomic, and neuroendocrine responses by CRF infusions in rats. Pharmacol Biochem Behav 77: 447-455.

Cole BJ, Cador M, Stinus L, Rivier J, Vale W, Koob GF et al (1990). Central administration of a CRF antagonist blocks the development of stress-induced behavioral sensitization. Brain Res 512: 343-346.

Cordero MI, Venero C, Kruyt ND, Sandi C (2003). Prior exposure to a single stress session facilitates subsequent contextual fear 
conditioning in rats: evidence for a role of corticosterone. Horm Behav 44: 338-345.

Cousins MS, Salamone JD (1994). Nucleus accumbens dopamine depletions in rats affect relative response allocation in a novel cost/benefit procedure. Pharmacol Biochem Behav 49: 85-91.

Del Arco A, Ronzoni G, Mora F (2015). Hypofunction of prefrontal cortex NMDA receptors does not change stress-induced release of dopamine and noradrenaline in amygdala but disrupts aversive memory. Psychopharmacology 232: 2577-2586.

Denk F, Walton ME, Jennings KA, Sharp T, Rushworth MFS, Bannerman DM (2005). Differential involvement of serotonin and dopamine systems in cost-benefit decisions about delay or effort. Psychopharmacology 179: 587-596.

de Quervain DJ, Roozendaal B, McGaugh JL (1998). Stress and glucocorticoids impair retrieval of long-term spatial memory. Nature 394: 787-790.

Diamond DM, Rose GM (1994). Stress impairs LTP and hippocampal-dependent memory. Ann NY Acad Sci 746: 411-414.

Dunn AJ (1988). Stress-related changes in cerebral catecholamine and indoleamine metabolism: lack of effect of adrenalectomy and corticosterone. J Neurochem 51: 406-412.

Dunn AJ, Berridge CW (1987). Corticotropin-releasing factor administration elicits a stress-like activation of cerebral catecholaminergic systems. Pharmacol Biochem Behav 27: 685-691.

Dunn AJ, Berridge CW (1990). Physiological and behavioral responses to corticotropin-releasing factor administration: is CRF a mediator of anxiety or stress responses? Brain Res Rev 15: 71-100.

Farrar AM, Segovia KN, Randall PA, Nunes EJ, Collins LE, Stopper $\mathrm{CM}$ et al (2010). Nucleus accumbens and effort-related functions: Behavioral and neural markers of the interactions between adenosine A2A and dopamine D2 receptors. Neuroscience 166: 1056-1067.

Floresco SB, Tse ML, Ghods-Sharifi S (2008). Dopaminergic and glutamatergic regulation of effort-and delay-based decision making. Neuropsychopharmacology 33: 1966-1979.

Ghods-Sharifi S, Floresco SB (2010). Differential effects on effort discounting induced by inactivations of the nucleus accumbens core or shell. Behav Neurosci 124: 179-191.

Grieder TE, Herman MA, Contet C, Tan LA, Vargas-Perez H, Cohen A. et al (2014). VTA CRF neurons mediate the aversive effects of nicotine withdrawal and promote intake escalation. Nat Neurosci 17: 1751-1758.

Hauger RL, Risbrough V, Oakley RH, Olivares-Reyes JA, Dautzenberg FM (2009). Role of CRF receptor signaling in stress vulnerability, anxiety, and depression. An NY Acad Sci 1179: 120-143.

Holly EN, DeBold JF, Miczek KA (2015). Increased mesocorticolimbic dopamine during acute and repeated social defeat stress: Modulation by corticotropin releasing factor receptors in the ventral tegmental area. Psychopharmacology 232: 4469-4479.

Imperato A, Puglisi-Allegra S, Casolini P, Angelucci L (1991). Changes in brain dopamine and acetylcholine release during and following stress are independent of the pituitary-adrenocortical axis. Brain Res 538: 111-117.

Jackson ME, Moghaddam B (2004). Stimulus-specific plasticity of prefrontal cortex dopamine neurotransmission. J Neurochem 88: 1327-1334.

Jedema HP, Moghaddam B (1994). Glutamatergic control of dopamine release during stress in the rat prefrontal cortex. J Neurochem 63: 785-788.

Kalin NH, Sherman JE, Takahashi LK (1988). Antagonism of endogenous $\mathrm{CRH}$ systems attenuates stress-induced freezing behavior in rats. Brain Res 457: 130-135.

Kalivas PW, Duffy P, Latimer LG (1987). Neurochemical and behavioral effects of corticotropin-releasing factor in the ventral tegmental area of the rat. J Pharmacol Exp Ther 242: 757-764.
Kim JJ, Lee HJ, Welday AC, Song EY, Cho J, Sharp PE et al (2007). Stress-induced alterations in hippocampal plasticity, place cells, and spatial memory. Proc Natl Acad Sci USA 104: 18297-18302.

Koob GF (2010). The role of CRF and CRF-related peptides in the dark side of addiction. Brain Res 1314: 3-14.

Krahn DD, Gosnell BA, Grace M, Levine AS (1986). CRF antagonist partially reverses CRF-and stress-induced effects on feeding. Brain Res Bull 17: 285-289.

Larkin JD, Jenni NL, Floresco SB (2015). Modulation of risk/reward decision making by dopaminergic transmission within the basolateral amygdala. Psychopharmacology 233: 121-136.

Lavicky J, Dunn AJ (1993). Corticotropin-releasing factor stimulates catecholamine release in hypothalamus and prefrontal cortex in freely moving rats as assessed by microdialysis. J Neurochem $\mathbf{6 0}$ : 602-612.

Lemos JC, Wanat MJ, Smith JS, Reyes BAS, Hollon NG, Van Bockstaele EJ et al (2012). Severe stress switches CRF action in the nucleus accumbens from appetitive to aversive. Nature 490: $402-406$.

Liu X (2015). Enhanced motivation for food reward induced by stress and attenuation by corticotrophin-releasing factor receptor antagonism in rats: Implications for overeating and obesity. Psychopharmacology 232: 2049-2060.

Lodge DJ, Grace AA (2005). Acute and chronic corticotropinreleasing factor 1 receptor blockade inhibits cocaine-induced dopamine release: Correlation with dopamine neuron activity. J Pharm Exper Therapeutics 314: 201-206.

Matsuzaki I, Takamatsu Y, Moroji T (1989). The effects of intracerebroventricularly injected corticotropin releasing factor (CRF) on the central nervous system: behavioral and biochemical studies. Neuropeptides 13: 147-155.

Müller MB, Zimmermann S, Sillaber I, Hagemeyer TP, Deussing JM, Timpl P et al (2003). Limbic corticotropin-releasing hormone receptor 1 mediates anxiety-related behavior and hormonal adaptation to stress. Nat Neurosci 6: 1100-1107.

Murphy FC, Rubinsztein JS, Michael A, Rogers RD, Robbins TW, Paykel ES et al (2001). Decision-making cognition in mania and depression. Psychol Med 31: 679-693.

Nawata Y, Kitaichi K, Yamamoto T (2012). Increases of CRF in the amygdala are responsible for reinstatement of methamphetamine-seeking behavior induced by footshock. Pharmacol Biochem Behav 101: 297-302.

Nemeroff CB, Widerlöv E, Bissette G, Walléus H, Karlsson I, Eklund $\mathrm{K}$ et al (1984). Elevated concentrations of CSF corticotropin-releasing factor-like immunoreactivity in depressed patients. Science 226: 1342-1344.

Nowend KL, Arizzi M, Carlson BB, Salamone JD (2001). D1 or D2 antagonism in nucleus accumbens core or dorsomedial shell suppresses lever pressing for food but leads to compensatory increases in chow consumption. Pharmacol Biochem Behav 69: 373-382.

Olausson P, Kiraly DD, Gourley SL, Taylor JR (2013). Persistent effects of prior chronic exposure to corticosterone on rewardrelated learning and motivation in rodents. Psychopharmacology 225: 569-577.

Pabst S, Brand M, Wolf OT (2013). Stress and decision making: A few minutes make all the difference. Behav Brain Res 250: 39-45.

Piantadosi PT, Khayambashi S, Schluter MG, Kutarna A, Floresco SB (2016). Perturbations in reward-related decision-making induced by reduced prefrontal cortical GABA transmission: Relevance for psychiatric disorders. Neuropharmacology 101: 279-290.

Porcelli AJ, Delgado MR (2009). Acute stress modulates risk taking in financial decision making. Psych Sci 20: 278-283.

Rodaros D, Caruana DA, Amir S, Stewart J (2007). Corticotropinreleasing factor projections from limbic forebrain and paraventricular nucleus of the hypothalamus to the region of the ventral tegmental area. Neuroscience 150: 8-13. 
Rubinsztein JS, Michael A, Paykel ES, Sahakian BJ (2000). Cognitive impairment in remission in bipolar affective disorder. Psychol Med 30: 1025-1036.

Salamone JD, Steinpreis RE, McCullough LD, Smith P, Grebel D, Mahan K (1991). Haloperidol and nucleus accumbens dopamine depletion suppress lever pressing for food but increase free food consumption in a novel food choice procedure. Psychopharmacology 104: 515-521.

Salamone JD, Koychev I, Correa M, McGuire P (2015). Neurobiological basis of motivational deficits in psychopathology. Eur Neuropsychopharm 25: 1225-1238.

Salamone JD, Cousins MS, Bucher S (1994). Anhedonia or anergia? Effects of haloperidol and nucleus accumbens dopamine depletion on instrumental response selection in a T-maze cost/benefit procedure. Behav Brain Res 65: 221-229.

Salamone JD, Cousins MS, McCullough LD, Carriero DL, Berkowitz RJ (1994). Nucleus accumbens dopamine release increases during instrumental lever pressing for food but not free food consumption. Pharm, Biochem Behav 49: 25-31.

Shafiei N, Gray M, Viau V, Floresco SB (2012). Acute stress induces selective alterations in cost/benefit decision-making. Neuropsychopharmacology 37: 2194-2209.

Shansky RM, Rubinow K, Brennan A, Arnsten AF (2006). The effects of sex and hormonal status on restraint-stress-induced working memory impairment. Behav Brain Function 2: b35.

Shors TJ, Weiss C, Thompson RF (1992). Stress-induced facilitation of classical conditioning. Science 257: 537-539.

Sokolowski JD, Salamone JD (1998). The role of accumbens dopamine in lever pressing and response allocation: effects of 6-OHDA injected into core and dorsomedial shell. Pharmacol Biochem Behav 59: 557-566.

Stahl SM (2002). The psychopharmacology of energy and fatigue. J Clin Psychiatry 63: 7-8.

Starcke K, Wolf OT, Markowitsch HJ, Brand M (2008). Anticipatory stress influences decision making under explicit risk conditions. Behav Neurosci 122: 1352-1360.

St. Onge JR, Abhari H, Floresco SB (2011). Dissociable contributions by prefrontal D1 and D2 receptors to risk-based decision making. J Neurosci 31: 8625-8633.

Stopper CM, Floresco SB (2011). Contributions of the nucleus accumbens and its subregions to different aspects of risk-based decision making. Cogn Affect Behav Neurosci 11: 97-112.

Stopper CM, Floresco SB (2014). What's better for me? Fundamental role for lateral habenula in promoting subjective decision biases. Nat Neurosci 17: 33-35.

Stopper CM, Tse ML, Montes DR, Wiedman CR, Floresco SB (2014). Overriding phasic dopamine signals redirects action selection during risk/reward decision making. Neuron 84: 177-189.

Treadway MT, Bossaller N, Shelton RC, Zald DH (2012). Effortbased decision-making in major depressive disorder: A translational model of motivational anhedonia. J Abnorm Psych 121: 553-558.

Tylee A, Gastpar M, Lépine JP, Mendlewicz J (1999). DEPRES II (Depression Research in European Society II): a patient survey of the symptoms, disability and current management of depression in the community. Int Clin Psychopharmacol 14: 139-151.

Twining RC, Wheeler DS, Ebben AL, Jacobsen AJ, Robble MA, Mantsch JR et al (2015). Aversive stimuli drive drug seeking in a state of low dopamine tone. Biol Psychiatry 77: 895-902.

Ungless MA, Singh V, Crowder TL, Yaka R, Ron D, Bonci A (2003). Corticotropin-releasing factor requires CRF binding protein to potentiate NMDA receptors via CRF receptor 2 in dopamine neurons. Neuron 39: 401-407.

Van Pett K, Viau V, Bittencourt JC, Chan RK, Li HY, Arias C et al (2000). Distribution of mRNAs encoding CRF receptors in brain and pituitary of rat and mouse. J Comp Neurol 428: 191-212.

Van't Veer A, Yano JM, Carroll FI, Cohen BM, Carlezon WA (2012). Corticotropin-releasing factor (CRF)-induced disruption of attention in rats is blocked by the $\kappa$-opioid receptor antagonist JDTic. Neuropsychopharmacology 37: 2809-2816.

Vranjkovic O, Gasser PJ, Gerndt CH, Baker DA, Mantsch JR (2014). Stress-induced cocaine seeking requires a beta-2 adrenergic receptor-regulated pathway from the ventral bed nucleus of the stria terminalis that regulates CRF actions in the ventral tegmental area. J Neurosci 34: 12504-12514.

Wanat MJ, Bonci A, Phillips PEM (2013). CRF acts in the midbrain to attenuate accumbens dopamine release to rewards but not their predictors. Nat Neurosci 16: 383-385.

Wanat MJ, Hopf FW, Stuber GD, Phillips PE, Bonci A (2008). Corticotropin-releasing factor increases mouse ventral tegmental area dopamine neuron firing through a protein kinase C-dependent enhancement of Ih. J Physiol 586: 2157-2170.

Wang B, Shaham Y, Zitzman D, Azari S, Wise RA, You ZB (2005). Cocaine experience establishes control of midbrain glutamate and dopamine by corticotropin-releasing factor: a role in stressinduced relapse to drug seeking. J Neurosci 25: 5389-5396.

Williams CL, Buchta WC, Riegel AC (2014). CRF-R2 and the heterosynaptic regulation of VTA glutamate during reinstatement of cocaine seeking. J Neuro 34: 10402-10414.

Yuen EY, Liu W, Karatsoreos IN, Feng J, McEwen BS, Yan Z (2009). Acute stress enhances glutamatergic transmission in prefrontal cortex and facilitates working memory. Proc Nat Acad Sci USA 106: 14075-14079.

Supplementary Information accompanies the paper on the Neuropsychopharmacology website (http://www.nature.com/npp) 